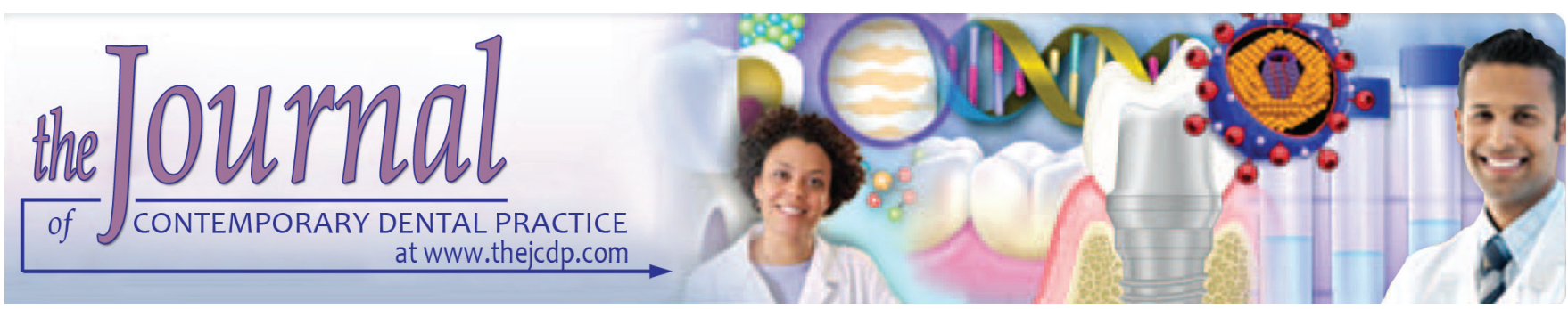

\title{
Effect of Green Tea Varnish on Depth of Root Caries
}

\author{
${ }^{1}$ Fahimeh Daneshyar, ${ }^{2}$ Zahra Khamverdi, ${ }^{3}$ Tayebeh Toliat, ${ }^{4}$ Mohammad Y Alikhani
}

\section{ABSTRACT}

Aim: Root caries is a common, debilitating condition particularly in the elderly population, which can lead to tooth loss. Evidence shows that green tea has cariostatic effects. Considering the gap of information on green tea varnish, this study aimed to assess the efficacy of green tea varnish in the prevention of root caries.

Materials and methods: This in vitro experimental study was performed on 42 sound premolars. Two layers of acid-resistant nail varnish were applied on root surfaces except for a window of $1 \times$ $4 \mathrm{~mm}$. The teeth were randomly divided into three groups $(n=14)$. Group I (control) received no intervention. Group II received green tea varnish applied on the roots every 48 hours for 21 days. Group III received green tea varnish every 24 hours for 21 days. Sections of $40 \mu$ thickness were prepared from the center of the window, and the depth of carious lesion was measured in three points with $500 \mu$ distance from each other using polarized light microscope. Data were analyzed using Statistical Package for the Social Sciences (SPSS) version 16 and nonparametric Kruskal-Wallis and Mann-Whitney U tests $(\alpha=0.05)$.

Results: The mean (and standard deviation) depth of carious lesion was $54.30 \pm 28.64(\mu \mathrm{m}), 0$, and 0 in groups I, II, and III respectively. Control group showed the highest depth of caries. Groups II and III were not significantly different in this respect, but significant differences were noted in depth of caries between groups I and II and also groups I and III ( $p<0.001)$.

Conclusion: Based on the results, the green tea varnish may possess anticariogenic effects on root caries when applied every

${ }^{1}$ Department of Pediatric Dentistry, Dental Faculty, Hamadan University of Medical Sciences, Hamadan, Islamic Republic of Iran

${ }^{2}$ Member of Dental Research, Department of Operative Dentistry, Dental Faculty, Hamadan University of Medical Sciences, Hamadan, Islamic Republic of Iran

${ }^{3}$ Department of Industrial Pharmaceutical Laboratory, School of Pharmacy, Tehran University of Medical Sciences, Tehran Islamic Republic of Iran

${ }^{4}$ Department of Microbiology, Dental Faculty, Hamadan University of Medical Sciences, Hamadan, Islamic Republic of Iran

Corresponding Author: Zahra Khamverdi, Member of Dental Research, Department of Operative Dentistry, Dental Faculty Hamadan University of Medical Sciences, Hamadan, Islamic Republic of Iran, Phone: +989183122095, e-mail: zkhamverdi@ yahoo.ca
24 or 48 hours over a 21-day period. Application of green tea varnish every 24 or 48 hours for 21 days may prevent root caries.

Clinical significance: Application of green tea varnish can prevent root caries.

Keywords: Dental caries, Green tea, Root surface, Varnish.

How to cite this article: Daneshyar F, Khamverdi Z, Toliat T, Alikhani MY. Effect of Green Tea Varnish on Depth of Root Caries. J Contemp Dent Pract 2018;19(2):137-142.

Source of support: Nil

Conflict of interest: None

\section{INTRODUCTION}

Root caries is a common, debilitating condition, particularly in the elderly population. ${ }^{1}$ This infectious disease is caused by colonization of bacteria and initiated by decalcification of the inorganic part of the tooth structure, which is followed by the destruction of the organic matrix. ${ }^{2-6}$ Root caries can also result in tooth loss, ${ }^{7,8}$ which negatively affects the quality-of-life of patients, particularly the elderly. ${ }^{9,10}$ Tooth decay is a multifactorial disease ${ }^{11}$ caused by the complex interaction of cariogenic oral flora and fermentable carbohydrates accumulating on tooth surfaces over time. ${ }^{12}$

Evidence shows that fluoride varnish can cause a 33\% reduction in the rate of caries. ${ }^{13}$ Furthermore, it has been reported that varnish is more efficient than fluoride gel in prevention of caries due to higher durability and easier and faster application. ${ }^{14}$ The use of varnishes made of organic materials is another strategy suggested for caries prevention.

Camellia sinensis, widely known as green tea, ${ }^{15}$ has anticancer, antioxidant, anti-inflammatory, and medicinal properties due to having catechin. The anticariogenic mechanisms of green tea have been partly understood. ${ }^{16-18}$ Duration of exposure of tooth structure to green tea affects its cariostatic efficacy. Thus, to benefit from its cariostatic effects, green tea must be used in a form with maximum durability on the tooth surface. ${ }^{2}$ 
Narotzki et al ${ }^{19}$ and Araghizadeh et $\mathrm{al}^{20}$ evaluated and confirmed the inhibitory effects of green tea on cariogenic bacteria. Ferrazzano et $\mathrm{al}^{21}{ }^{21}$ in their in vivo study, evaluated the antimicrobial effect of green tea extract on cariogenic microflora. Since varnish provides longer exposure than solutions and mouthrinses ${ }^{22,23}$ and considering the lack of information on the efficacy of green tea varnish on caries formation, this study sought to assess the effect of green tea varnish on the depth of root caries. The null hypothesis was that green tea varnish would have no significant effect on depth of root caries.

\section{MATERIALS AND METHODS}

This in vitro experimental study was conducted on premolar teeth extracted due to orthodontic or periodontal reasons in the past few months. Immediately after extraction, the teeth were immersed in $10 \%$ formalin (Shahid Ghazi Co., Tabriz, Islamic Republic of Iran) at room temperature for 1 week for disinfection. After 1 week, the teeth surfaces were cleaned of soft tissue, debris, and calculus using a periodontal curette (Juya, Kashmir, Pakistan) and polished with a nonfluoridated pumice paste (Golchadent Co., Karaj, Islamic Republic of Iran) and rubber cup (Kerr, California, USA). ${ }^{24}$ At 24 hours before the experiment, root surfaces were inspected under a stereomicroscope (Eclipse E 600, Nikon, Tokyo, Japan) at $20 \times$ magnification. The inclusion criteria were the absence of cracks, caries, restorations, or congenital anomalies. Totally, 42 sound teeth were chosen. Two layers of acidresistant nail varnish were applied on root surfaces except for a window measuring $1 \times 4 \mathrm{~mm}$ (due to limitations in root shape and contour, only one window was considered on the buccal or lingual surface of the roots).$^{25}$ The teeth were randomly divided into three groups $(n=15)$ based on the method of surface treatment:

1. Group I: The teeth did not undergo any intervention (control group)

2. Group II: Green tea varnish was applied on root surfaces every 48 hours for 21 days

3. Group III: Green tea varnish was applied on root surfaces every 24 hours for 21 days $^{2}$

The three groups were marked with three different colors of acid-resistant nail varnish.

To prepare $5 \%$ green tea varnish, $100 \mathrm{mg}$ of the powdered catechin of green tea (epigallocatechin-3-gallate (EGCG), Sigma-Aldrich, USA) was added to $2 \mathrm{~mL}$ of ethyl cellulose and ethanol in a 1:1 ratio. After 1 hour of sonication for homogenization, it was refrigerated at 2 to $5^{\circ} \mathrm{C}$ in a dark container.

The teeth in each group were placed in three different-coded containers and autoclave-sterilized at $121^{\circ} \mathrm{C}$ and 15 psi pressure for $15 \mathrm{~min}$. Microbrushes used for varnish application were also sterilized with the same method used for sterilizing the teeth. Next, each tooth was separately placed in brain heart infusion broth containing $1.5 \times 10^{8}$ Streptococcus mutans bacteria (equal to 0.5 McFarland concentration), $1.5 \times 10^{8}$ lactobacilli (equal to 0.5 McFarland concentration), and $3 \mathrm{~mL}$ of $20 \%$ sucrose solution, and was incubated. ${ }^{2}$ To ensure nill contamination and assess the growth and proliferation of S. mutans and lactobacilli, samples were taken off the plates between 10 and 11 am and cultured on blood agar. No contamination was noted in any group during the study period. In S. mutans plates, $10 \mathrm{~mL}$ of the culture medium was replaced with $10 \mathrm{~mL}$ of fresh medium every other day to provide nutrients for the bacteria. $^{2}$

For application of green tea varnish in group II, the teeth were removed from the medium once every 48 hours, rinsed under distilled water, and dried. One layer of varnish was applied on the root surfaces by a microbrush and allowed to dry for 60 seconds. Next, the teeth were immersed again in the medium. In group III, this process was performed once every 24 hours for 21 days. After completion of this period, the teeth were rinsed with distilled water, mounted in acrylic resin (Acropars, Tehran, Islamic Republic of Iran), and horizontally sectioned at the center of the window into $300 \mu \mathrm{m}$ slices by a microtome (Hammarlund-Essler, Stockholm, Sweden). Final polishing was done to obtain an ideal thickness of $40 \mu \mathrm{m}$ using 120 to 1,500 grit paper disks. The thickness of slices was measured by a precise digital caliper (Mitutoyo 12" /300 mm, Japan) with $0.01 \mathrm{~mm}$ resolution. The teeth were then immersed in distilled water to remove debris. For histological assessment of sections, distilled water was used as the background substance, and the specimens were observed under a light microscope (SoloMark 900x, Ningbo, China) with a polarized filter at $\times 10$ magnification. ${ }^{25}$ Diameter of the field of view was measured to be $1,500 \mu$ using a Neubauer slide under the microscope. This value was used as a reference unit for measurement of the depth of carious lesions. Caries depth in each specimen was measured in three points with $500 \mu$ distance from each other using AutoCAD software (Autodesk AutoCAD 2016) by an oral and maxillofacial pathologist. The mean depth in the three points was calculated and considered as the depth of lesion in each specimen (Figs 1 and 2). ${ }^{24,26}$ After calculating the depth of demineralization in the three groups, data were analyzed using SPSS version 16 and nonparametric Kruskal-Wallis and MannWhitney test. Level of significance was set at 0.05 .

\section{RESULTS}

Table 1 shows descriptive statistics in the three groups. As shown in Table 1, the mean depth of carious lesion 


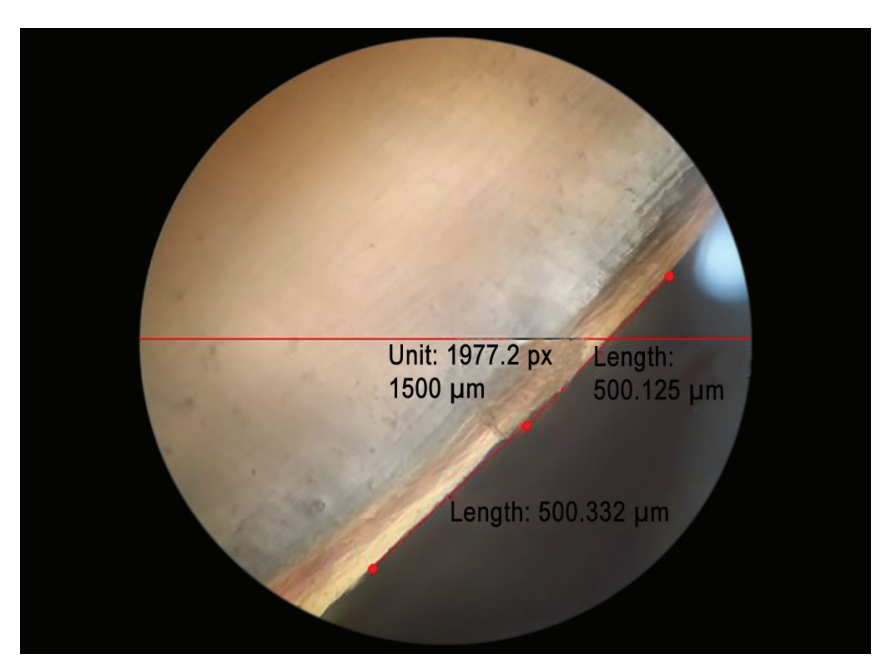

Fig. 1: Polarized microscope view in noncarious specimen indicates no carious lesion, and the surface is intact

Table 1: Descriptive analysis of the carious lesion depth $(n=14)$

\begin{tabular}{lllll}
\hline Groups & $\begin{array}{l}\text { Mean } \\
(\mu \mathrm{m})\end{array}$ & $\begin{array}{l}\text { Standard } \\
\text { deviation }(\mu \mathrm{m})\end{array}$ & $\begin{array}{l}\text { Minimum } \\
(\mu \mathrm{m})\end{array}$ & $\begin{array}{l}\text { Maximum } \\
(\mu \mathrm{m})\end{array}$ \\
\hline Control (group I) & $54 / 30$ & $28 / 64$ & $8 / 75$ & $94 / 30$ \\
Varnish every & 0 & 0 & 0 & 0 \\
$\begin{array}{l}48 \text { hours (group II) } \\
\text { Varnish every }\end{array}$ & 0 & 0 & 0 & 0 \\
24 hours (group III) & & & & \\
\hline
\end{tabular}

was the highest in the control group compared with the other groups (Graph 1). In varnish groups, no carious lesion was noted at 24 or 48 hours.

Since data were not normally distributed in the three groups, Kruskal-Wallis test was used for comparison of the three groups, and Mann-Whitney U test was applied for pairwise comparisons. The Kruskal-Wallis test showed that the three groups were significantly different in terms of depth of carious lesion $(p<0.001)$. The Mann-Whitney U test showed that depth of caries was not significantly different between groups II and III. However, the group subjected to varnish application every 24 hours had a significant difference from the control group $(\mathrm{p}<0.001)$. Furthermore, group II (varnish application every 48 hours) had a significant difference from the control group (group I) in the depth of caries $(\mathrm{p}<0.001)$.

\section{DISCUSSION}

Root caries can negatively affect oral health and compromise on the quality-of-life of the elderly population..$^{9,10}$ Exposure of cervical dentin due to gingival margin recession commonly occurs as the result of improper toothbrushing, use of abrasive toothpastes, or frequent use of toothpicks. Dental erosion, periodontal procedures, such as gingival surgery, scaling, and root planning, and prosthetic, orthodontic, and restorative treatments, such

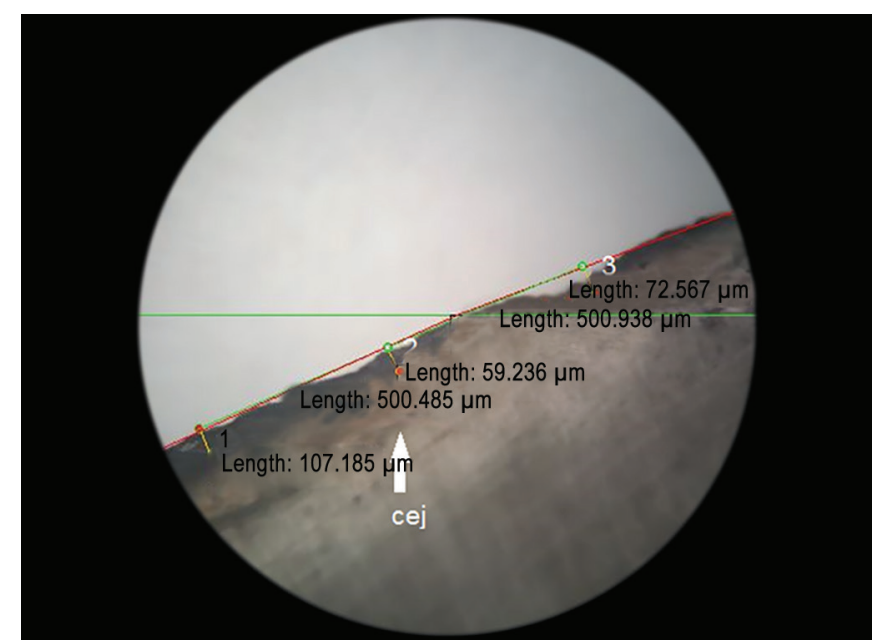

Fig. 2: Polarized microscope view indicates different depths of caries in a carious specimen

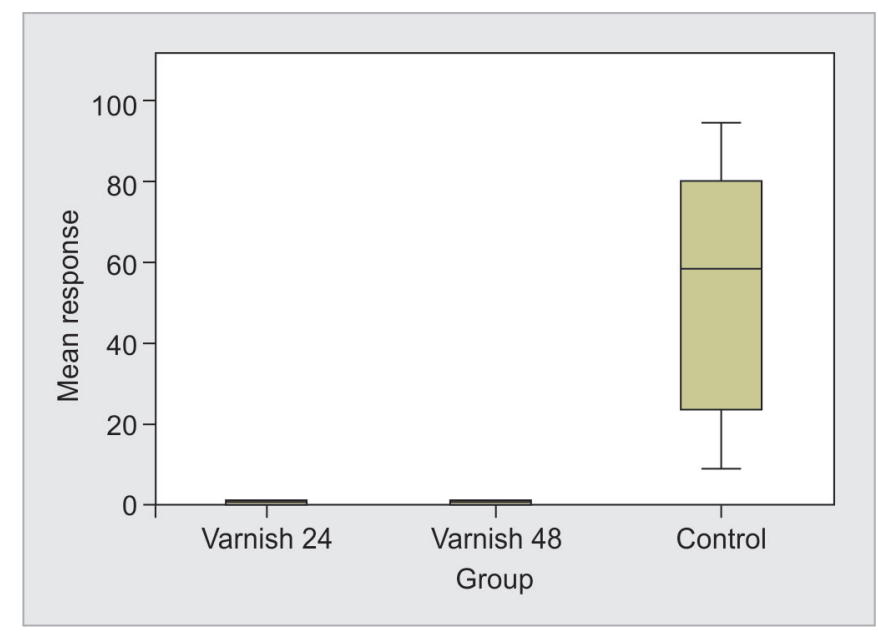

Graph 1: Comparison of depth of caries in the studied groups in $\mu \mathrm{m}$

as tooth whitening, can also increase the risk of root caries. ${ }^{27-30}$ Margins of the cavitated root caries are often placed in both enamel and dentin, and restoration of these cavities has a failure rate of $68 \%$ in 12 months since there is no restorative material that can provide suitable bond to both enamel and dentin. These carious lesions are often asymptomatic and close to dental pulp. ${ }^{31}$ Thus, their prevention is a priority for both dentists and patients. This study evaluated the efficacy of green tea varnish in the prevention of root caries.

Several organic compounds are available for root caries prevention; however, their application is affected by many other factors, such as their stability, odor, taste, and affordability, which must be taken into account. ${ }^{32-35}$ Green tea extract is a natural compound that possesses all the aforementioned properties. ${ }^{33}$ Of the catechins available in the chemical composition of green tea, EGCG is the most abundant. ${ }^{34}$ Tea catechins are water soluble and colorless comprising 25 to $40 \%$ of the solid solutes in tea. ${ }^{36}$ Green tea 
has many beneficial properties for the treatment of cardiac diseases and obesity. ${ }^{16,17}$ Anticarcinogenic properties of green tea have also been confirmed. ${ }^{36-38}$ Since EGCG is the most active component of green tea extract, ${ }^{39}$ it was used as the green tea extract in our study. Furthermore, polarized light was used to assess the depth of caries due to advantages, such as no necessity for slide preparation and high accuracy. ${ }^{40,41}$ Since the minimum duration of time required for the development of initial noncavitated carious lesions (first clinical evidence of demineralization) is 21 days, ${ }^{24,42}$ the 21 -day period was considered for development of caries in this study, and mineralization depth was measured by a polarized light microscope.

The reducing potential of each polyphenol compound depends on the number of its hydroxyl groups. Although green and black tea are excellent sources of polyphenols, antioxidant properties of green tea are 5 times higher than those of other types of tea due to it having higher concentrations of polyphenols rich in hydroxyls. ${ }^{43}$ Furthermore, it can inhibit matrix metalloproteinase (MMP) enzymes. These enzymes are capable to hydrolyze the organic matrix of demineralized dentin ${ }^{44,45}$ such that MMP-2 (gelatinase A), MMP-8 (collagenase), MMP-9 (gelatinase B), and MMP-20 (Enamelysin) are involved in the process of caries, and destruction occurs by activation of MMPs. ${ }^{39,44,45}$ Chatterjee et $\mathrm{al}^{46}$ showed that green tea promotes periodontal health by decreasing inflammation, preventing bone loss, and inhibiting the growth and proliferation of some specific bacteria. Previous studies on the properties of this material and its efficacy for prevention of tooth erosion are limited. Kato et $\mathrm{al}^{47}$ and Magalhães et $\mathrm{al}^{48}$ evaluated bovine teeth and concluded that green tea extract can effectively prevent dental caries. Similarly, the present study showed that there is a significant difference between the control and green tea groups in terms of depth of carious lesions.

Some previous in vitro and in vivo studies on animals and humans have evaluated the effects of green tea on S. mutans. ${ }^{34,35,44,49}$ Araghizadeh et al, ${ }^{20}$ in their in vitro study, evaluated the effect of green tea extract on cariogenic bacteria. They showed that $S$. mutans were totally sensitive to green tea and it can decrease their activity and consequently prevent the development of carious lesions to a great extent. In fact, polyphenols present in green tea contain high levels of catechins and theaflavins and have very strong antibacterial properties. ${ }^{50}$ Some other studies have evaluated the anticariogenic properties of green tea by assessing its direct effect on microorganisms. ${ }^{51}$ In vitro studies have shown that catechins present in green tea prevent adhesion of Streptococci to tooth surfaces. Otake et $\mathrm{al}^{52}$ concluded that Sunphenon (a commercial mixture of catechins extracted from green tea leaves) prevents adhesion of $S$. mutans to hydroxyapatite disks covered with saliva. Similar results were reported by Xiao et $\mathrm{al}^{53}$ which confirm the favorable properties of green tea. Another suggested mechanism for anticariogenic properties of green tea is by the inhibition of glucosyltransferase and amylase enzymes. ${ }^{51}$ These enzymes play an important role in dental caries pathogenesis. Zhang and Shen ${ }^{54}$ concluded that green tea extract decreases the activity of amylase enzyme in the human saliva, which leads to cariostatic effects. Another study indicated that drinking one to three cups of green tea per day decreases dental caries and plaque formation on tooth surfaces. ${ }^{55}$ No previous study has evaluated the effect of green tea varnish on prevention of root caries. Several studies with different methodologies have evaluated anticariogenic effects of green tea, and almost all of them reported the capacity of green tea to inhibit dental caries. Goenka et $\mathrm{al}^{56}$ and also Suzuki et $\mathrm{al}^{57}$ showed that individuals who frequently drink green tea have fewer missing teeth, lower prevalence of caries, and more favorable oral hygiene. You ${ }^{58}$ reported that $0.2 \%$ green tea used as a mouthwash or with toothbrushing for 5 minutes significantly decreased plaque index. Hattarki et $\mathrm{al}^{59}$ evaluated over 6,000 children in the United Kingdom and concluded that green tea definitely decreases the prevalence of caries since it inhibits cariogenic microorganisms. This has also been reported in a review article by Jones et $\mathrm{al}^{60}$

Suyama et $\mathrm{al}^{61}$ used this extract for making chewing gums and evaluated the effects of chewing green tea gums on building tooth resistance to acid attacks. They concluded that chewing green tea gums increases the resistance of dentin to acid. Our study showed that application of green tea varnishes every 24 or 48 hours completely prevented the development of caries. The two green tea groups were not significantly different in this respect, which is probably due to the high durability of green tea varnish on the tooth surface for up to 48 hours. The highest depth of caries was noted in the control group.

However, the results of this study were in contrast to those of Rezaei-Soufi et $\mathrm{al}^{2}$ because they had reported that green tea mouthwash had no significant effect on dental caries. The difference in the results of the two studies may be due to the difference in methodologies since we used green tea varnish, which appears to have more durability than a mouthwash and provides longer exposure. In our study, the effect of toothbrushing during the determined time period ${ }^{62}$ was not evaluated on teeth and this was a limitation; this factor should be evaluated in future studies to assess the cariostatic properties of green tea when combined with toothbrushing to obtain more reliable results. Another limitation was the type of study. The present study was designed as an in vitro study and could not fully simulate the clinical setting. Thus, clinical studies are required to confirm the obtained results. 
Another point to be noted is that a specific concentration of green tea extract was used in this study; future studies are recommended to use other concentrations of green tea varnish to shorten the time interval between applications.

\section{CONCLUSION}

Within the limitations of the present study, the green tea varnish may possess anticariogenic effect on root caries when applied every 24 or 48 hours within a 21-day period.

\section{ACKNOWLEDGMENT}

This study was part of a thesis (9411136365) approved by the Student Research Committee of Hamadan University of Medical Sciences. The authors would like to express their gratitude to this committee.

\section{REFERENCES}

1. Griffin SO, Griffin PM, Swann JL, Zlobin N. Estimating rates of new root caries in older adults. J Dent Res 2004 Aug;83(8):634-638.

2. Rezaei-Soufi L, Rafieian N, Jazaeri M, Abdolsamadi H, Kasraei S, Alikhani M-U. Comparison of the anticaries effect of polyphenol extract of green tea with $0.05 \%$ fluoride, $0.2 \%$ cholorhexidine and fluoride-cholorhexidine, an in vitro study. J Mash Dent Sch 2013;36:301-308.

3. Arora A, Evans RW. Is the consumption of fruit cariogenic? J Investig Clin Dent 2012 Feb;3(1):17-22.

4. Devulapalle KS, Mooser G. Glucosyltransferase inactivation reduces dental caries. J Dent Res 2001 Feb;80(2):466-469.

5. Heymann, HO.; Swift, EJ Jr.; Ritter, AV. Sturdevant's art and science of operative dentistry. St. Louis: Elsevier Health Sciences; 2014. p. 12.

6. Rajendran, R. Shafer's textbook of oral pathology. New Delhi: Elsevier India; 2009.

7. Fure S, Zickert I. Incidence of tooth loss and dental caries in 60-, 70-and 80-year-old Swedish individuals. Community Dent Oral Epidemiol 1997 Apr;25(2):137-142.

8. Slade GD, Gansky SA, Spencer AJ. Two-year incidence of tooth loss among south Australians aged 60+ years. Community Dent Oral Epidemiol 1997 Dec;25(6):429-437.

9. Slade GD, Spencer AJ, Locker D, Hunt RJ, Strauss RP, Beck JD. Variations in the social impact of oral conditions among older adults in south Australia, Ontario, and north Carolina. J Dent Res 1996 Jul;75(7):1439-1450.

10. Slade GD, Spencer AJ, Roberts-Thomson K. Tooth loss and chewing capacity among older adults in Adelaide. Aust N Z J Public Health 1996 Feb;20(1):76-82.

11. Burne RA. Oral streptococci. Products of their environment. J Dent Res 1998 Mar;77(3):445-452.

12. Featherstone JD. The science and practice of caries prevention. J Am Dent Assoc 2000 Jul;131(7):887-899.

13. Davies GM, Bridgman C, Hough D, Davies RM. The application of fluoride varnish in the prevention and control of dental caries. Dent Update 2009 Sep;36(7):410-412.

14. Schmit JL, Staley RN, Wefel JS, Kanellis M, Jakobsen JR, Keenan PJ. Effect of fluoride varnish on demineralization adjacent to brackets bonded with RMGI cement. Am J Orthod Dentofacial Orthop 2002 Aug;122(2):125-134.
15. Sudano Roccaro A, Blanco AR, Giuliano F, Rusciano D, Enea V. Epigallocatechin-gallate enhances the activity of tetracycline in staphylococci by inhibiting its efflux from bacterial cells. Antimicrob Agents Chemother 2004 Jun;48(6):1968-1973.

16. An BJ, Kwak JH, Son JH, Park JM, Lee JY, Jo C, Byun M-W. Biological and anti-microbial activity of irradiated green tea polyphenols. Food Chem 2004 Dec;88(4):549-555.

17. De Moraes MD, Carneiro JR, Passos VF, Santiago SL. Effect of green tea as a protective measure against dental erosion in coronary dentine. Braz Oral Res 2016;30:1-16.

18. Percival RS, Devine DA, Duggal MS, Chartron S, Marsh PD. The effect of cocoa polyphenols on the growth, metabolism, and biofilm formation by Streptococcus mutans and Streptococcus sanguinis. Eur J Oral Sci 2006 Aug;114(4):343-348.

19. Narotzki B, Reznick AZ, Aizenbud D, Levy Y. Green tea: a promising natural product in oral health. Arch Oral Biol 2012 May;57(5):429-435.

20. Araghizadeh A, Kohanteb J, Fani MM. Inhibitory activity of green tea (Camellia sinensis) extract on some clinically isolated cariogenic and periodontopathic bacteria. Med Princ Pract 2013;22(4):368-372.

21. Ferrazzano GF, Roberto L, Amato I, Cantile T, Sangianantoni G, Ingenito A. Antimicrobial properties of green tea extract against cariogenic microflora: an in vivo study. J Med Food 2011 Sep;14(9):907-911.

22. Monteith V, Millett D, Creanor S, Gilmour W. Fluoride release from orthodontic bonding agents: a comparison of three in vitro models. J Dent 1999 Jan;27(1):53-61.

23. Todd MA, Staley RN, Kanellis MJ, Donly KJ, Wefel JS. Effect of a fluoride varnish on demineralization adjacent to orthodontic brackets. Am J Orthod Dent Orthop 1999 Aug;116(2):159-167.

24. Ahmadi-Motamayel F, Rezaei-Soufi L, Kiani L, Alikhani MY, Poorolajal J, Moghadam M. Effects of honey, glucose, and fructose on the enamel demineralization depth. J Dent Sci 2013;8(2):147-150.

25. Hong L, Watkins CA, Ettinger RL, Wefel JS. Effect of topical fluoride and fluoride varnish on in vitro root surface lesions. Am J Dent 2005 Jun;18(3):182-187.

26. Farhadian N, Miresmaeili A, Soufi LR, Baghaei F, Shahvali E. $\mathrm{CO}_{2}$ laser effects on shear bond strength of orthodontic brackets and enamel demineralization. Iran Assoc Orthod J 2010;5(1):24-31.

27. Brodowski D, Imfeld T. Dentin hypersensitivity-a review. Schweizer Monatsschrift für Zahnmedizin 2003;113(1):49-58.

28. Ganss C. Definition of erosion and links to tooth wear. Monogr Oral Sci 2006;20:9-16.

29. Haywood VB. Treating sensitivity during tooth whitening. Compend Contin Educ Dent 2005 Sep;26(9 Suppl 3):11-20.

30. Hypersensitivity CABoD. Consensus-based recommendations for the diagnosis and management of dentin hypersensitivity. J Can Dent Assoc 2003 Apr;69(4):221-226.

31. Wierichs R, Meyer-Lueckel H. Response to letter to the editor. Systematic review on noninvasive treatment of root caries lesions. J Dent Res 2015 Feb;94(2):1168-1169.

32. Li J, Zhan L, Barlow J, Lynch R, Zhou X, Liu T. Effect of tea polyphenol on the demineralization and remineralization of enamel in vitro. J Sichuan Univ Med Sci Ed 2004 May;35(3):364-366.

33. Llorach R, Urpi-Sarda M, Rotches-Ribalta M, Rabassa M, Andres-Lacueva C. Resveratrol from dietary intake to promising therapeutic molecule. Agro Food Indus HiTech 2010 Mar-Apr;21(2):42-44. 
34. Łuczaj W, Skrzydlewska E. Antioxidative properties of black tea. Prev Med 2005 Jun;40(6):910-918.

35. Milgrom P, Riedy C, Weinstein P, Tanner A, Manibusan L, Bruss J. Dental caries and its relationship to bacterial infection, hypoplasia, diet, and oral hygiene in 6-to 36-month-old children. Community Dent Oral Epidemiol 2000 Aug;28(4): 295-306.

36. Imai K, Suga K, Nakachi K. Cancer-preventive effects of drinking green tea among a Japanese population. Prev Med 1997 Nov-Dec;26(6):769-775.

37. Jankun J, Selman SH, Swiercz R, Skrzypczak-Jankun E. Why drinking green tea could prevent cancer. Nature 1997 Jun;387:561.

38. Yamane T, Nakatani H, Kikuoka N, Matsumoto H, Iwata $Y$, Kitao Y, Oya K, Takahashi T. Inhibitory effects and toxicity of green tea polyphenols for gastrointestinal carcinogenesis. Cancer 1996 Apr;77(8 Suppl):1662-1667.

39. Huang CC, Wu WB, Fang JY, Chiang HS, Chen SK, Chen $\mathrm{BH}$, Chen YT, Hung CF. (-)-epicatechin-3-gallate, a green tea polyphenol is a potent agent against UVB-induced damage in haCaT keratinocytes. Molecules 2007 Aug;12(8): 1845-1858.

40. Arends J, ten Bosch JJ. Demineralization and remineralization evaluation techniques. J Dent Res 1992 Apr;71:924-928.

41. Tavassoli-Hojjati S, Haghgoo R, Mehran M, Niktash A. Evaluation of the effect of fluoride gel and varnish on the demineralization resistance of enamel: an in vitro. J Islamic Dent Assoc Iran (JIDAI) 2012;24(1):39-46.

42. Jazaeri M,PakdekF, Rezaei-Soufi L,Abdolsamadi H, Rafieian N. Cariostatic effect of green tea in comparison with common anticariogenic agents: an in vitro study. J Dent Res Dent Clin Dent Prosp 2015 Winter;9(1):44-48.

43. Chaussain-Miller C, Fioretti F, Goldberg M, Menashi S. The role of matrix metalloproteinases (MMPs) in human caries. J Dent Res 2006 Jan;85(1):22-32.

44. Cowan MM. Plant products as antimicrobial agents. Clin Microbiol Rev 1999 Oct;12(4):564-582.

45. Sartor L, Pezzato E, Dell'Aica I, Caniato R, Biggin S, Garbisa S. Inhibition of matrix-proteases by polyphenols: chemical insights for anti-inflammatory and anti-invasion drug design. Biochem Pharmacol 2002 Jul;64(2):229-237.

46. Chatterjee A, Saluja M, Agarwal G, Alam M. Green tea: a boon for periodontal and general health. J Indian Soc Periodontol 2012 Apr-Jun;16(2):161-167.

47. Kato MT, Magalhães AC, Rios D, Hannas AR, Attin T, Buzalaf MA. Protective effect of green tea on dentin erosion and abrasion. J Appl Oral Sci 2009 Nov-Dec;17(6):560-564.

48. Magalhães AC, Wiegand A, Rios D, Hannas A, Attin T, Buzalaf MA. Chlorhexidine and green tea extract reduce dentin erosion and abrasion in situ. J Dent 2009 Dec;37(12): 994-998.

49. Matsumoto M, Minami T, Sasaki H, Sobue S, Hamada S, Ooshima T. Inhibitory effects of oolong tea extract on cariesinducing properties of mutans streptococci. Caries Res 1999 Nov-Dec;33(6):441-445.

50. Yoshino K, Nakamura Y, Ikeya H, Sei T, Inoue A, Sano M, Tomita I. Antimicrobial activity of tea extracts on cariogenic bacterium (Streptococcus mutans). J Food Hyg Soc JAP 1996 Dec;37(2):104-108.

51. Ferrazzano GF, Amato I, Ingenito A, Zarrelli A, Pinto G, Pollio A, Pollio A. Plant polyphenols and their anti-cariogenic properties: a review. Molecules 2011 Feb;16(2):1486-1507.

52. Otake S, Makimura M, Kuroki T, Nishihara Y, Hirasawa M. Anticaries effects of polyphenolic compounds from Japanese green tea. Caries Res 1991;25(6):438-443.

53. Xiao Y, Liu T, Zhan L, Zhou X. The effects of tea polyphenols on the adherence of cariogenic bacterium to the salivary acquired pellicle in vitro. Hua Xi Kou Qiang Yi Xue Za Zhi 2000 Oct;18(5):336-339.

54. Zhang J, Shen X. Antioxidant activities of baicalin, green tea polyphenols and alizarin in vitro and in vivo. J Nutr Env Med 1997 Jul;7(2):79-89.

55. Wu CD. Tea and Oral Health. Prot Eff Tea Human Health 2006;2:200-206.

56. Goenka P, Sarawgi A, Karun V, Nigam AG, Dutta S, Marwah N. Camellia sinensis (Tea): implications and role in preventing dental decay. Pharmacogn Rev 2013 Jul-Dec;7(14):152-156.

57. Suzuki Y, Miyoshi N, Isemura M. Health-promoting effects of green tea. Proc Jpn Acad Ser B Phys Biol Sci 2012;88(3):88-101.

58. You SQ. Study on feasibility of Chinese green tea polyphenols (CTP) for preventing dental caries. Zhonghua Kou Qiang Yi Xue Za Zhi 1993 Jul;28(4):197-199.

59. Hattarki SA, Pushpa SP, Bhat K. Evaluation of the efficacy of green tea catechism as an adjunct to scaling and root planning in the management of chronic periodontitis using PCR analysis: a clinical and microbiological study. J Indian Soc Periodontol 2013 Mar;17(2):204-209.

60. Jones C, Woods K, Whittle G, Worthington H, Taylor G. Sugar, drinks, deprivation and dental caries in 14-year-old children in the north west of England in 1995. Community Dent Health 1999 Jun;16(2):68-71.

61. Suyama E, Tamura T, Ozawa T, Suzuki A, Iijima Y, Saito T. Remineralization and acid resistance of enamel lesions after chewing gum containing fluoride extracted from green tea. Aust Dent J 2011 Dec;56(4):394-400.

62. $\mathrm{Hu} \mathrm{W}$, Featherstone JD. Prevention of enamel demineralization: an in-vitro study using light-cured filled sealant. Am J Orthod Dentofacial Orthop 2005 Nov;128(5):592-600. 